\title{
Global Forum of Cancer Surgeons: Support for the Brazilian Society of Surgical Oncology Journey towards Implementation of Cytoreductive Surgery/Hyperthermic Intraperitoneal Chemotherapy in Brazil
}

\begin{abstract}
Alexandre Ferreira Oliveira, MD, $\mathrm{PhD}^{1,2}$, Claudio Almeida Quadros, $\mathrm{MD}, \mathrm{PhD}^{1,2}$, Héber Salvador de Castro Ribeiro, MD, PhD ${ }^{1,2}$, Alberto Julius Alves Wainstein, MD, PhD ${ }^{1}$, Bruno José de Queiroz Sarmento, MD ${ }^{1}$, Jorge Lyra, MD ${ }^{1}$, Glauco Baiocchi Neto, MD, PhD $^{1}$, Reitan Ribeiro, $\mathbf{M D}^{1}$, Rodrigo Nascimento Pinheiro, MD, Msc ${ }^{1}$, Elio José Silveira da Silva Barreto, MD ${ }^{1}$, Jason Park, MD $^{3}$, Andrew McKay, MD ${ }^{3}$, Arnab Gupta, MD $^{4}$, Dhairyasheel Savant, $\mathrm{MD}^{4}$, Aviram Nissan, $\mathrm{MD}^{5}$, Douglas Zippel, MD, FACS ${ }^{5}$, Augusto Leon, MD, MSCCh${ }^{6}$, Juan Enrique Bargallo-Rocha, $\mathbf{M D}^{2,7}$, Hector Martinez Said, $\mathrm{MD}^{2,7}$, Yuko Kitagawa, $\mathrm{MD}, \mathbf{P h D}^{\mathbf{8}}$, Kazuhiro Yoshida, MD, $\mathrm{PhD}^{8}$, Woo Yong Lee, MD, PhD ${ }^{9}$, Do Joong Park, MD, PhD ${ }^{9}$, Ashraf Zaghloul, $\mathbf{M D}^{10}$, Wael A. Gawad, MD, PhD ${ }^{10}$, Gong Chen, MD $^{11}$, Haroon Javaid Majid, MD, FRCS ${ }^{12}$, Muhammad Arshad Cheema, MD, FRCS ${ }^{12}$, Alessandro Gronchi, $\mathrm{MD}^{13}$, Tibor Kovacs, $\mathrm{MD}^{14}$, Domenico $\mathrm{D}^{\prime} U g o, \mathrm{MD}^{13,14}$, David L. Bartlett, MD, FSSO ${ }^{15}$, James R. Howe, MD, FSSO ${ }^{15}$, and Chandrakanth Are, MD, MBA, FSSO ${ }^{15}$

${ }^{1}$ Brazilian Society of Surgical Oncology, Rio de Janeiro, Brazil; ${ }^{2}$ Latin American Society of Surgical Oncology, Rio de Janeiro, Brazil; ${ }^{3}$ Canadian Society of Surgical Oncology, Toronto, ON, Canada; ${ }^{4}$ Indian Association of Surgical Oncology, Miraj, Maharashtra, India; ${ }^{5}$ Israeli Society of Surgical Oncology, Ramat Gan, Israel; ${ }^{6}$ Catholic University of Chile, Santiago, Chile; ${ }^{7}$ Sociedad Mexicana de Oncologia, Mexico City, Mexico; ${ }^{8}$ Japanese Society of Gastroenterological Surgery, Tokyo, Japan; ${ }^{9}$ Korean Society of Surgical Oncology, Goyang-si, Gyeonggi-do, Korea; ${ }^{10}$ Egyptian Society of Surgical Oncology, Cairo, Egypt; ${ }^{11}$ Chinese Society of Surgical Oncology, Beijing, China; ${ }^{12}$ Surgical Oncology Society Pakistan, Lahore, Pakistan; ${ }^{13}$ Italian Society of Surgical Oncology, Napoli, Italy; ${ }^{14}$ European Society of Surgical Oncology, Brussels, Belgium; ${ }^{15}$ Society of Surgical Oncology, Rosemont, IL
\end{abstract}

Brazil is the largest and most populous nation in South America. The estimated population in 2020 is approximately 212 million, with a life expectancy of 74.7 years. ${ }^{1}$ For the year 2018, there were 559,371 new cancer cases, with 243,588 cancer-related deaths. ${ }^{2,3}$ It is estimated that by the year 2040, the number of new cancer cases will increase to 998,056 and will be associated with 476,272 cancer-related deaths. The top five cancers by incidence are

(C) Society of Surgical Oncology 2021

First Received: 16 November 2020

Accepted: 15 December 2020;

Published Online: 18 January 2021

C. Are, MD, MBA, FSSO

e-mail: care@unmc.edu breast, prostate, lung, colon and thyroid, with lung, breast, prostate, stomach, and colon accounting for the most cancer-related deaths.

In 2014, the total health expenditure in Brazil was US $\$ 947$ per capita; of this, $46 \%$ and $54 \%$ were allotted for the public and private health care systems respectively. ${ }^{4}$ The Brazilian Unified Health System is one of the largest in the world, providing health care coverage for nearly $70-80 \%$ of the Brazilian population. The health care model in Brazil is a hybrid of both public (free health care service - Brazilian Public Health System [Sistema Único de Saúde, or SUS]) and private systems (for the high-income population), which function in a complementary fashion. The private health care system consists of health care plans and insurance policies. Through its hospitals, clinics, laboratories, and private offices, the private health care system is able to offer more access to a comprehensive range of 
expensive medications and surgical procedures, and also expensive novel treatment options such as cytoreductive surgery and hyperthermic intraperitoneal chemotherapy (CRS/HIPEC).

Although the public and private health care systems function in a parallel and complementary fashion, there are inherent inequities in care delivery between the two systems. The Brazilian Public Health System (SUS), which provides care for nearly 180 million Brazilians, is unable to match the comprehensive range of care provided in the private health system. This results in disparities in care between patients who access care through the public or private health systems, with the former at a disadvantage. As a result, the majority of the Brazilian population who use the Brazilian Public Health System (SUS) do not have access to expensive therapies such as CRS/HIPEC.

Pseudomyxoma peritonei (PMP) and malignant mesothelioma are rare tumors, both globally and in Brazil. Bustamante-Teixeira et al. ${ }^{5}$ utilized the population-based cancer registry of Sao Paulo, Brazil, to document the incidence of rare cancers as defined by the RARECARE list. ${ }^{6}$ Over a period of 15 years (1997-2012), these researchers documented 52 cases of fibromyxoma and lowgrade mucinous adenocarcinoma (PMP) of the appendix, and 234 cases of malignant mesothelioma. The Globocan 2018 database documented 196 new cases and 119 mesothelioma-related deaths in Brazil in 2018, which likewise attests to the rarity of the disease. ${ }^{3}$ The rarity of these cancers in comparison with the more common cancers such as breast, prostate, and lung can influence the awareness and resources allotted to treating these patients.

Malignant peritoneal mesothelioma (MPM) is a rare disease that is confined to the peritoneal cavity, with minimal evidence of spread to the liver or beyond the peritoneal cavity. The morbidity and survival associated with this rare cancer is therefore dependent on the peritoneal burden of disease. Systemic therapy has minimal impact on survival in patients with MPM. Despite the lack of level I evidence, some studies have shown benefit of CRS/HIPEC in the treatment of MPM. ${ }^{7-10}$ In a systematic review/meta-analysis, Helm et al. noted a 5-year survival rate of $42 \%$, although the heterogeneity of studies precludes generalization. ${ }^{11}$. In the review by Sugarbaker, ${ }^{7}$ CRS/HIPEC combined with normothermic intraperitoneal chemotherapy long-term (NIPEC-LT) has been shown to be associated with a 5-year survival rate of $70 \%$ in carefully selected patients. The Chicago Consensus Working Group noted that after adequate cross-sectional imaging, fit-for-surgery patients with epithelioid mesothelioma (or extremely well-selected biphasic or sarcomatoid mesothelioma) should be offered CRS/HIPEC. ${ }^{12}$
CRS/HIPEC can also be considered for the treatment of PMP associated with appendiceal lesions ${ }^{13}$ or from other organs such as the ovary, ${ }^{14}$ colon, ${ }^{15}$ and stomach. ${ }^{16}$ The Chicago Consensus Working Group noted that for patients with low-grade mucinous neoplasms (grade 1) of the appendix, CRS/HIPEC is the treatment of choice and that excellent long-term survival can be accomplished even with a high disease burden in the setting of complete cytoreduction.

In Brazil, it is estimated that an annual case load of 400-600 cases of PMP and MPM experience a delay in treatment due to the non-inclusion of CRS/HIPEC among the procedure list (treatment options) reimbursed by the Brazilian Public Health System (SUS). This lack of reimbursement has prevented the development of specialized centers of excellence for CRS/HIPEC and the required referral pathways in the Brazilian Public Health System (SUS).

As a result, several lawsuits were initiated by patients in different Brazilian states, prompting the Brazilian Ministry of Health to reconsider its position on reimbursement for CRS/HIPEC. The Brazilian Ministry of Health tasked the Federal Council of Medicine to review the current literature and develop a formal position on the role and inclusion of CRS/HIPEC in the treatment paradigm of PMP and MPM.

In 2017, the Brazilian Federal Medical Council published a technical note recognizing that the treatment of peritoneal disease has evolved greatly in recent years. ${ }^{17}$ The incorporation of new locoregional, systemic, and multimodal therapies has shifted the natural history of peritoneal tumors and brought hope to patients and their families, despite the lack of high-quality randomized controlled trials. CRS/HIPEC was approved by the Brazilian Federal Medical Council, with level of evidence III and degree of recommendation $\mathrm{B}$, for the treatment of peritoneal pseudomyxoma and malignant mesothelioma. ${ }^{17}$

The next step in the pathway to make CRS/HIPEC available to patients in Brazil was to include this on the list of procedures reimbursed by the Brazilian Public Health System (SUS). The first step in this process was a public discussion organized by the National Commission for the Incorporation of Technologies (CONITEC) to gather opinions about CRS/HIPEC. CONITEC is the official agency in Brazil that is responsible for adding any new therapeutic option into the Brazilian Public Health System (SUS) coverage. The Brazilian Society of Surgical Oncology (BSSO) was integrally involved in this entire process and played a paramount role by providing the relevant supporting scientific data and pharmacoeconomic analyses to CONITEC, with the support of the Brazilian National Cancer Institute. To help with these efforts, the BSSO approached the Global Forum of Cancer Surgeons 
(GFCS) in October 2019, at the mid-cycle meeting of the GFCS conducted during the bi-annual BSSO meeting in Rio de Janeiro, to provide a 'Statement of Support' that could be used by the BSSO to support the CONITEC for inclusion of CRS/HIPEC in the Brazilian Public Health System (SUS).

The GFCS was formed under the auspices of the Society of Surgical Oncology (SSO) in 2017. ${ }^{18}$ The mission of the GFCS is to provide a voice for cancer surgeons to improve surgical care for cancer patients through multidisciplinary care, education research, outreach, advocacy, and leadership on the global stage. ${ }^{19-21}$ The GFCS consists of 15 leading surgical oncology societies from across the world, ${ }^{22}$ and these member societies represent $>75 \%$ of the global cancer burden, by incidence and mortality.

The GFCS provided a "Statement of Support" for the BSSO in December 2019, to be used in its supportive efforts with CONITEC. This important 'Statement of Support' was helpful in the discussions with the CONITEC with regard to the assimilation of new technology and procedures. The 'Statement of Support' from the GFCS, combined with letters of support from other specialists in the field from across the world, helped to build a broad consensus and to convince the CONITEC to incorporate CRS/HIPEC into the Brazilian Public Health System (SUS) in $2019 .^{23,24}$

As a result of these efforts, CRS/HIPEC is now included in the list of procedures reimbursed by the Brazilian Public Health System (SUS) in the treatment algorithm of PMP and MPM. CRS/HIPEC will be reimbursed in a similar vein to liver transplantation, to the tune of US\$14,000 (quality-adjusted life-years, two times the gross domestic product). At present, the Brazilian Ministry of Health is undertaking studies to understand the logistics, financing, and auditing to facilitate the streamlined introduction of CRS/HIPEC into the Brazilian Public Health system (SUS). Efforts are also underway to identify Centers of Excellence for each state within the country. It is proposed that each state designates two Centers of Excellence; however, for states with a larger population, it has been decided to designate one Center of Excellence for each 10 million citizens.

The primary reason that fueled the birth of the GFCS was to provide a single, cohesive, and powerful global voice for surgeons to advocate and advance safe and timely cancer surgery on the global stage. This successful effort of incorporating CRS/HIPEC into the Brazilian Public Health System (SUS) is a reaffirmation of the mission of the GFCS. It is also a powerful testament to the important role that the GFCS can play on the global stage. We hope that the GFCS will continue to advocate for cancer surgery on the global stage so that every patient can have access to safe, timely, and affordable surgical care regardless of their socioeconomic status or geographic location.

ACKNOWLEDGMENTS The authors acknowledge the following persons for their support towards this initiative: Marcello Deraco, MD; Yan Li, MD, PhD; Brendan Morgan, MCh, FRCS, FRCSI, D.MED; and Prof. Dr. Med Beate Rau, MBA.

DISCLOSURES Yuko Kitagawa: Chugai Pharmaceutical Co., Ltd. Taiho Pharmaceutical Co., Ltd. Yakult Honsha Co. Ltd. Asahi Kasei Pharma Corporation. Otsuka Pharmaceutical Co., Ltd. Takeda Pharmaceutical Co., Ltd. Ono Pharmaceutical Co., Ltd. Tsumura and Co. Kyouwa Hakkou Kirin Co., Ltd. Dainippon Sumitomo Pharma Co., Ltd. EA Pharma Co., Ltd. Astellas Pharma Inc. Toyama Chemical Co., Ltd. Medicon Inc. Kaken Pharmaceutical Co., Ltd. Otsuka Pharmaceutical Factory Inc. Eisai Co., Ltd. Teijin Pharma Limited. Nihon Pharmaceutical Co., Ltd. Nippon Covidien Inc. Shionogi \& Co., Ltd. Taisho Toyama Pharmaceutical Co., Ltd. Sanofi K.K. Chandrakanth Are: Pfizer, educational grant. Patent for laparoscopy device.

\section{REFERENCES}

1. Central Intelligence Agency. The World Factbook. https://www.c ia.gov/library/publications/the-world-factbook/geos/br.html. Accessed 14 Aug 2020.

2. International Agency for Research on Cancer. Global Cancer Observatory. Available at: https://gco.iarc.fr/. Accessed 14 Aug 2020.

3. International Agency for Research on Cancer. Brazil. Source: Globocan 2020. Available at: https://gco.iarc.fr/today/data/facts heets/populations/76-brazil-fact-sheets.pdf. Accessed 14 Aug 2020.

4. Figueiredo JO, et al. Gastos público e privado com saúde no Brasil e países selecionados. Saúde em Debate. 2018;42(n. spe2);37-47.

5. Bustamante-Teixeira MT, Latorre MR, Guerra MR, et al. Incidence of rare cancers in the city of Sao Paulo. Brazil Tumori. 2019;105:22-30.

6. RARECARE: Surveillance of rare cancers in Europe. http://ww w.rarecare.eu/rarecancers/rarecancers.asp. Accessed 14 Aug 2020.

7. Sugarbaker PH. Update on the management of malignant peritoneal mesothelioma. Transl Lung Cancer Res. 2018;7(5):599-608. https://doi.org/10.21037/tlcr.2018.08.03.

8. Baratti D, Kusamura S, Cabras AD, Bertulli R, Hutanu I, Deraco M. Diffuse malignant peritoneal mesothelioma: long-term survival with complete cytoreductive surgery followed by hyperthermic intraperitoneal chemotherapy (HIPEC). Eur J Cancer. 2013;49(15):3140-8. https://doi.org/10.1016/j.ejca.2013. 05.027.

9. Sugarbaker PH, Chang D. Long-term regional chemotherapy for patients with epithelial malignant peritoneal mesothelioma results in improved survival. Eur J Surg Oncol. 2017;43(7):1228-35. h ttps://doi.org/10.1016/j.ejso.2017.01.009.

10. Sugarbaker PH, Stuart OA. Unusually favorable outcome of 6 consecutive patients with diffuse malignant peritoneal mesothelioma treated with repeated doses of intraperitoneal paclitaxel. A case series. Surg Oncol. 2020;33:96-9. https://doi.org/10.1016/j. suronc.2020.01.009.

11. Helm JH, Miura JT, Glenn JA, et al. Cytoreductive surgery and hyperthermic intraperitoneal chemotherapy for malignant 
peritoneal mesothelioma: a systematic review and meta-analysis. Ann Surg Oncol. 2015;22(5):1686-93. https://doi.org/10.1245/s 10434-014-3978-x.

12. Schuitevoerder D, Izquierdo FJ, Plana A, et al. The Chicago consensus on peritoneal surface malignancies: management of peritoneal mesothelioma. Ann Surg Oncol. 2020;27:1774-9.

13. Schuitevoerder D, Plana A, Izquierdo FJ, et al. The Chicago consensus on peritoneal surface malignancies: management of appendiceal neoplasms. Ann Surg Oncol. 2020;27:1753-60.

14. Hoppenot C, Schuitevoerder D, Izquierdo FJ, et al. The Chicago consensus on peritoneal surface malignancies: management of ovarian neoplasms. Ann Surg Oncol. 2020;27:1780-7.

15. Izquierdo FJ, Schuitevoerder D, Plana A, et al. The Chicago consensus on peritoneal surface malignancies: management of colorectal metastases. Ann Surg Oncol. 2020;27:1761-7.

16. Izquierdo FJ, Schuitevoerder D, Plana A, et al. The Chicago consensus on peritoneal surface malignancies: management of gastric metastases. Ann Surg Oncol. 2020;27:10768-1773.

17. Conselho Federal De Medicina (CFM). https://sistemas.cfm.org.b r/normas/arquivos/pareceres/BR/2017/6_2017.pdf

18. Are C, Coit DG, McMasters KM, et al. Global forum of cancer surgeons: declaration of intent. Ann Surg Oncol. 2017;24:2429-31.
19. Are C, McMasters KM, Giuliano A, et al. Global forum of cancer surgeons: a steady voice for cancer surgeons to improve surgical care for cancer patients globally. Ann Surg Oncol. 2018;25:2114-6.

20. Are C, McMasters KM, Giuliano A, et al. Global forum of cancer surgeons: perspectives on barriers to surgical care for cancer patients and potential solutions. Ann Surg Oncol. 2019;26:1577-82.

21. Are C, Bartlett DL, Nissan A, et al. Global forum of cancer surgeons: position statement to promote cancer surgery globally. Ann Surg Oncol. 2020;27:2573-6.

22. https://www.surgonc.org/global-outreach/global-forum-of-cancer -surgeons/. Accessed 23 Aug 2020.

23. Conitec. http://conitec.gov.br/images/Relatorios/2020/Relatorio_ HIPEC_Pseudomixioma_FINAL_518_2020.pdf

24. Conitec. http://conitec.gov.br/images/Relatorios/2020/Relatorio_ HIPEC_Mesotelioma_FINAL_517_2020.pdf

Publisher's Note Springer Nature remains neutral with regard to jurisdictional claims in published maps and institutional affiliations. 